\title{
11. The Torments of Initiation and the Question of Resistance ${ }^{1}$
}

\author{
Thomas A. Gregor
}

\begin{abstract}
We are told that in certain happy regions of the earth, where nature provides in abundance everything that man desires, there are races whose life is passed in tranquillity and who know neither compulsion nor aggressiveness. I can scarcely believe it, and should be happy to meet these fortunate beings.
\end{abstract}

— Sigmund Freud, Letter to Albert Einstein, 'Why War?'

\section{The Problem}

In 1982 Donald Tuzin published a short but trenchant article titled, 'Ritual Violence Among the Arapesh: The Dynamics of Moral and Religious Uncertainty'. The work probes a question of broad human significance. The Ilahita Arapesh, in the course of their long initiatory cycles, terrorised their children and subjected them to excruciating ordeals. Tuzin self-consciously ascribes the word 'brutal' to these acts, partly because many of the Ilahita themselves so saw them, but also because we, if we are honest with ourselves, do so as well. Ilahita ritual (which no longer takes place) was particularly disturbing in that it was at the sacred core of the society.

Rituals of initiation, which encompass many discomforting practices, are the centrepiece of religious life among many Melanesian societies. It is in the course of initiation that young men learn the deepest secrets of the men's cults, that they come to possess its most sacred symbols, and that they learn the most profound values of the society. When we consider that initiation can last many years (in the case of Ilahita, it is a 50-year cycle), we only hyperbolise slightly when we say that ritual, in many Melanesian societies, is initiation. What does it mean when such ritual encompasses the cruelties that Tuzin and others have documented? How, Tuzin asks, can such 'good people do bad things to one another?' (1982:323). Consider, as an example, the Ilahita custom of laf, or ritual killing. During one of the stages of initiation, wearers of certain ritual masks who are possessed by the spirit of the men's cult, may kill people with impunity:

1 This material was based partly upon work supported by the National Science Foundation under Grant No. 0650859. The article has also benefited from the comments of Warren Shapiro. 
'nothing can vacate a hamlet so quickly as one of these spooks materializing out of the gloom of the surrounding jungle.' The 'heaviness' of the mask transforms its wearer into a compulsive killer: 'his own child or brother would not be spared if he came upon them' (Tuzin 1980:50).

Are we dealing with social pathology, and, if so, how can a relativistic discipline such as ours, especially one that, as Tuzin put it, 'make[s] no provision for affect' (1982:320), even begin to describe it?

Ritual violence is not wholly strange to us in that religious violence is familiar territory. It is responsible for the deaths of millions, and it confronts us in each day's news. But religious violence is invariably, in terms of its ideology, defensive in nature. Hence those who die in its service are martyrs to the cause, destined to a place in heaven, as in the case of jihad in radical Islam or the crusaders during the eleventh century. Seen from the point of view of the perpetrator, such violence defends the religion against its external enemies.

Religious violence might also turn inward, as in the persecution of heretics. There are abundant historical examples in Western Christianity, culminating in the Inquisition. But here, too, looked at from the perspective of the inquisitors, we find the religion defending itself, albeit by turning upon the enemy within.

Ritual violence, unlike religious violence, neither guards the periphery of religion nor assures the purity of its core. Our only experience with it, as Tuzin points out, is in highly sublimated versions such as those associated with the Eucharist. Violence directed against the self-as in self-mortification described in Catholic liturgy - comes closer, but it too, while discomforting, is largely alien territory.

Tuzin suggests that, as anthropologists, we practice our own sublimations, in that ritual violence becomes an unexamined part of the background of ethnographic accounts. To be sure, the ethnography is plain enough, but the moral and emotional implications of the violence are often rendered nearly invisible by theoretical frameworks that anaesthetise us from feeling (Tuzin 1982:322). 'One problem entailed in studying the literature of an ethnographic area such as New Guinea', he writes,

is that the reader risks being desensitized-losing his cultural distance and with it his 'fresh eye'. Penile incision is reported often in the New Guinea ethnography. The resulting contempt-bred-of-familiarity takes the form of coming to view this practice as 'just another' customary observance equivalent in most analytic respects to members of the culture brushing their teeth with coconut husks or marrying their cross-cousins. (Tuzin 1980:67) 
There are exceptions among ethnographers - notably Tuzin himself, but also Read (1954, 1965) and especially Gilbert Herdt, who writes of his own 'shock, fear, anger and sorrow in the rituals' (Herdt 1981a:7). More normally, such reactions stay well separate from the accounts. Although Tuzin does not state it, this is useful in that it permits description free from extraneous judgment. But it comes at a cost in that it numbs us to the reactions of those we study. Are they so different from us that they do not perceive the violence they perpetrate as cruel? And if so, why do the tormented eventually turn upon their children and pass the suffering to the next generation?

My intention is to examine these questions from the perspective of research in Melanesia, which offers many relevant examples. The reader is warned that my focus is primarily on a few societies where the data are rich, and the level of ritual pain is extreme. The question I will address is that of resistance. Is there evidence that those who perpetuate the torments of initiation question what they are doing? Do they feel remorse for what they have done or shame for its effects? The puzzle of ritual violence and the possibility of resistance reflect on our capacity to love and empathise, on broad issues of ethical relativism and on the universality of human values.

\section{The Background of Ritual Violence: Male initiation in Melanesia}

Male initiation is about making men out of boys. Ritual violence, therefore, occurs in a larger sexualised context. Roger Keesing (1982:6-13) and Gregor and Tuzin (2001) summarise the characteristics of male initiation rituals, many of which can be reasonably extended to cultures beyond Melanesia. The most salient fact is that in ritually violent cultures males and females are different kinds of beings in their physiology, their bodily fluids and their essences (Keesing 1982:7). These contrasts radiate outwards so that the mythology, folk medicine and expressive culture are themselves, in Shirley Lindenbaum's (1987:222) useful phrase, 'gender inflected', so that 'the polarities of male and female articulate cosmic forces thought to be located in the human body'. Outside Melanesia, the pattern is less marked but still vivid. The most cosmic example of which I am aware is in Amazonia, where the Tukuna regard the phallic sun god as being in permanent copulation with the womb-like under layer of the cosmos, which is constantly being fertilised by his semen in the form of the sun's rays.

The primary symbolic currency of the initiatory symbolism is formed by sexual body parts and fluids. They appear not as rooted in different sexual natures but as permutations, one of the other. Penises, clitorises, vaginas, anuses, breasts, mouths, noses and tongues condense, merge and differentiate. Among the 
Sambia, semen is equated with breast milk: 'the milk of women is the same as milk of men' (Herdt 1981a:186-7). The penis, as the source of milk, is referred to as the 'glans-breast'.

The initiatory systems we will examine are 'pseudo-procreative' (Hiatt 1971) in that men coopt women's capacity to gestate and give birth to new life. Growth and manhood are achieved through giving birth to initiates, through injecting them with life substance, especially through the oral ingestion of semen. The concept of pseudo-procreativity is literalised most vividly in the practice of subincision among the Australian Arunta (Arrernte), wherein the initiators drip 'postpartum' blood from their newly opened subincision scars, which are called vaginas, and the blood is identified as postpartum blood (Hiatt 1971). Among the Iatmul, 'male initiators are identified as "mothers" of the novices' and the doorway to the initiatory structure is literally the 'clitoris gate' (Bateson 1958:282). A similar pattern is repeated among the Wogeo in the form of male 'menstruation' and in many other Melanesian and Amazonian contexts, albeit in slightly less intense and elaborate forms (see, for example, Gregor 1985). A logical corollary is the disturbing possibility of male pregnancy, which is a fear expressed by Sambia (Herdt 1981b:237) and the Awa (Newman and Boyd 1982). There seem to be few limits to the ingeniousness of initiators in claiming the generative capacity of women (see Bettelheim's [1954] more general treatment).

These ideas are images of dreams, the stuff of primary process thought. As relativising anthropologists, we rarely say it, but they are factually wrong, they are based on 'error' (Keesing 1982), and they are, in fact, objectively 'preposterous' (Hays 1988). Nonetheless they have real consequences for initiates, for women and for the moral systems they infuse. Thus, the men who utilise feminine symbolism in the creation of initiates are not grateful. Women are dangerous. They and their menstrual blood are contaminating. The overwhelming burden of the ideology of the initiating cults is that women are inimical to masculinity and, in Tuzin's words, 'the bane of a peaceful society' (1980:106). The process of initiation strips away all that is feminine from boys who have been too long in association with their mothers, through rituals that purge female influence from their skin, blood, intestinal tracts, words and thoughts.

In a few cultures, the opposition and uneasy relationship of men and women spill over from initiation to appear in other areas of social life, with women often being the victim of male aggression. Among the Nama, as described by Read (1954:22-3), 'women suspected of adultery have sticks thrust into their vaginas...fights are staged at marriages, when, characteristically enough, a man is required to shoot an arrow into the thigh of his future wife'. Sexual violence itself is encompassed in an atmosphere where aggression is a norm. Again following Read (1954:33), 'punishment for wrongdoing characteristically includes public beatings and vicious humiliations...self-injury and mutilation 
are customary ways of expressing sorrow and loss... dominance and submission, rivalry and coercion are constantly recurring themes, manifest alike in day-today contexts and in ceremon[y].'

\section{The Torments of Initiation}

The ideology of masculinity and sexual opposition sets the stage for ritual violence within the cycle of initiation. Boys are not simply roughly treated. Rather they are systematically terrorised. Let us look at the process from the perspective of the novices.

\section{Lack of Preparation or Explanation}

Initiates are often unprepared for what will happen to them. Cruel treatment, once explained, becomes bearable, and initiation has a high purpose of making men from boys. But, as I read the literature, the explanation often comes after the torment. Hence among the Awa, 'the sequence of male initiation begins when these boys are forcefully taken to the men's house... The boys are surprised by this abduction' (Newman and Boyd 1982:247). Adult men, recalling the experience, describe themselves as unprepared: 'they cried and shook when taken away to the men's ground' (Newman and Boyd 1982). Further along in the process of initiation, the boys have learned to expect abuse, so much so that anticipation itself becomes anguish. Recalling such a moment, one of the men says: 'There was something else besides washing. We heard that, and we all started to shake' (Newman and Boyd 1982:253). Similarly, Tuzin (1980:94) describes the novices as 'wondering what will happen' just prior to being forced to run a gauntlet in which they are rubbed with nettles and clubbed, some knocked unconscious.

On the occasion when children are prepared for the ritual, the story might be even more terrifying than the reality. Sambia boys are told 'the spirit wants to get you, she wants to kill and eat you!' (Herdt 1981a:110). Among the Ilahita, prior to having their penises lacerated, the boys are told that the Tambaran spirit will force them to 'slide down the spiked trunk of a falanga sago palm, and thus rip open their bellies' (Tuzin 1982:338). From a child's perspective, these stories are genuinely terrifying. The events associated with them must seem unpredictable, catastrophic and lethal. 


\section{Separation from Mothers}

We must keep in mind that the initiates are boys as young as six or seven, who will be separated from their mothers in seclusion camps or villages for periods of months or years. The tears of mothers as their sons are led away to initiation are thoroughly justified. Among the Sambia, after the boys learn (for the first time) that they must have oral sex with the bachelors to consume semen, they are marched in front of their mothers as novice warriors. This is the last time they will see their mothers and sisters for more than 10 years. Herdt explains that a boy loses his mother totally. Physical contact, commensality and even direct gaze are forbidden. Having learned the secrets of the cult, he is forbidden this warmth 'for fear he might reveal these secrets' (Herdt 1981a:112). In other cultural settings as well, the long process of initiation and the barriers between men and women seem sufficient for sons to 'forget' their mothers. When their mothers might see them again, they will have been forever changed.

\section{The Novices Are Guilty}

The first explanation the novices might receive for their torment is that it is their own fault: initiation is punishment for real and imagined misdeeds. Among the Sambia, Herdt notes that this is a formal part of the justification for the ritual: 'first-stage nose bleeding is a punishment for insolence', and the more defiant the child is to the initiators, the more he is tormented. The sense of retaliation is explicit, in that, in the words of a Sambia initiator, 'for those acts we now pay you back' (Herdt 1982:225). Among the Awa, the men harangue the boys for their purported misconduct and blame them for the deaths of warriors who were killed when they were too young to have participated in their defence. The men's anger at the boys is genuine: 'So great is [the patriclansmen's] hostility towards the boys that they are not allowed to be directly involved in the purging ritual lest they handle a nose bleeder, vomiting cane or bamboo blade in such a manner as to cause serious injury on their relatives' (Newman and Boyd 1982:283). Ilahita Arapesh initiators are equally furious at their charges, explaining to them that they are guilty and will be punished.

\section{Terrorisation: Staging}

Beyond separation is psychological terror, which is deliberately inflicted on the initiates. Among the most violent of the initiators, the Marind Anim ordeals included 'submitting them to an ostensible headhunt attack so realistic that most of them fainted' (Knauft 1993:150). Terror is enhanced by deliberate staging designed to produce fear, including frightening masks, strange sounds and seclusion enclosures with moveable walls. Herdt writes that among the Sambia 
the boys are tied on the backs of their sponsors so that escape is impossible. They then 'confront a massive vibrating wall of thick green foliage'. There is a bedlam of 'eerie sputtering sounds', shaking walls, and what seems to be blood dripping from the vegetation (Herdt 1981a:141). The boys are terrified and cry out for their mothers. Tuzin writes of the Arapesh:

What cannot be conveyed in a short space is the full emotional force of this violence: it is one thing to be thumped in the head or have your penis lacerated, but when these attacks are staged in a dramatic atmosphere of weird customary, unearthly sounds, and frenzied stomping, screaming and singing by scores of armed warriors, each of whom seems madly intent on your destruction, the experience is transformed into nightmarish horror. (Tuzin 1982:337)

What comes across in the literature is that the terror is not a by-product of necessary procedures, which are, regretfully, frightening. Often terror itself is the objective.

\section{Pain}

It is easy to inflict excruciating, unbearable pain. Pressure, heat and blows are sufficient. A device as simple as a water board can make it unbearable. But there is something quite different about ritual pain. It seems designed, often ingeniously, to violate self-boundaries, to humiliate and to induce terror and fear of death. Hence the torments focus on bodily orifices and boundariesusually the neurally most sensitive and intimate tissues, including the nostrils and nasal cavity, the mouth, throat and oesophagus, the genitals and, with somewhat less frequency, the eyes and the anus. The overwhelming theme is that of penetration and laceration, using sharpened canes, bamboo rods, tiny stone arrows and similar devices. A full catalogue of techniques is the stuff of nightmares. Alan Morinis, who has examined pain in initiatory rites, lists 'being beaten, starved, incised, scarified, pierced, tattooed, terrified, mutilated, circumcised, infibulated, cicatrized, bound, and subject to removal of parts of... bodies, especially teeth and fingers' (1985:151).

In Melanesia, it appears that initiators are more than commonly imaginative, in that they add such techniques as cane swallowing, nose bleeding and being rubbed with and forced to swallow nettles, and, at least among the Sambia, being forced, in the dark, without preparation, to have oral sex with strange adult men.

Of these ordeals, cane swallowing deserves special note. A photograph of Awa cane swallowing subtitled 'a man forces the vomiting cane down an initiate's throat' can be found in Newman and Boyd's (1982) article 'The Making of Men'. 
The canes penetrate more than a foot inside the throat and oesophagus, and they are intended to produce defecation and vomiting. Herdt (1981b:224) quotes an informant: 'This is for removing food belonging to the mother', which is the sweet potato, hence the term for 'cane swallowing' translates as 'sweet potato/ food; elimination'. Cane swallowing also is designed to induce defecation, which eliminates not only maternal food but also maternal symbols: 'Out with the feces pass the depreciating "words" of the mother' from which the boy must be separated (Herdt 1981b).

Closely associated with cane swallowing among the Sambia is nose bleeding (the term translates as 'cleansing and expulsion'), which is regarded as the most painful act. It is performed upon the boys 'without warning' in an assault so violent that it constitutes physical and psychical trauma (Herdt 1982). The boys' first experience with nose bleeding is horrific, and they cry out for their mothers. Adults recalling the experience are 'virtually unanimous in expressing the feeling that they believed they were to be killed on the spot' (Herdt 1982:225).

In all of the groups I have reviewed, the physical attacks on the boys inevitably turn to an assault on the genitals. One example is sufficient. Among the Ilahita Arapesh, the men make a surgical instrument 'by sharpening a piece of bamboo to a razor's edge' (Tuzin: 1980:69), which, when decorated, is the incisor of a ritual pig. The 'pig' — one of the initiators - is a 'balefully weird creature', his skin painted black. A mask covers the face. He lies in wait beneath the floor of the initiation chamber until called by the boys' sponsors. In the midst of shouting and singing designed to terrify the initiates and drown out their screams for their mothers, the pig suddenly appears 'to bite them'. The pig delivers 'deep cutting strokes on their glans penis' (Tuzin 1980:71). Younger boys, who watch in horror, are also attacked. They are 'held down while their penes and scrota are vigorously rubbed with singing nettles' (Tuzin 1982:338). Then all of the boys are thrown in a pool previously filled with stinging nettles (Tuzin 1982).

Beatings, cane swallowing, nose bleeding and assaults are often combined with each other and with still more excruciating patterns of abuse. Hence Van Baal reports that among the Marind Anim, initiates were the targets of anal rape and that they 'had their mouths, noses and eyes smeared with excrement that had been mixed with semen...they were forced to lie in seclusion until maggots appeared on their befouled faces' (Knauft 1993:150).

\section{Death}

Several ethnographers note that initiation is extremely dangerous for the boys, and some in fact die. Cane swallowing is known to be particularly risky in that it can cause internal haemorrhaging. We do not know how frequently 
boys actually die in the course of initiation, but it is not infrequent. Campbell (1983:144) reprints a historical photo from Arnhem Land showing the corpses of seven young initiates who died as a consequence of being 'exposed to a broiling sun and to a torment of stinging insects'.

\section{Explanations of the Torments of Initiation}

Ethnographers' explanations often focus on the role of initiation rituals in creating solidarity among the boys who have together survived the ordeal and their subordination to the power of the senior males. Initiation entails secrecy and gradual revelation of cult knowledge - a period of many months, years or even a lifetime, as in the case of the Ilahita. Those who breach the secrets may be put to death. The unity of men-held together by secrets and the common bonds of shared torment - is crucial in communities at war, which is traditionally a chronic state of affairs. Perhaps the logical extreme in this process is reached among the Sambia, who force the boys to have sex with the bachelors and thereby create homoerotic bonds among them. Pacification, as Herdt (1981a:210) predicted, brought the initiatory cycles to an end, and along with it aggression towards women.

More psychologically oriented approaches emphasise the peculiar role of pain in establishing solidary relationships (Morinis 1985), the repetitive compulsion in which trauma is mastered by inflicting it on others, and, specifically in the Melanesian context, 'flash-bulb memory', by which pain intensifies and engages the initiate with ritual experience (Whitehouse 1996).

\section{Resistance}

\section{Resistance}

The term 'resistance' has been overworked in the postmodern literature, and it rolls too easily off the tongue. Michael Brown (1996), in a perceptive essay, 'On Resisting "Resistance"', points out that a primary function of the concept has been to establish the user's moral bona fides as an objector to oppression. Brown notes that in the world of cultural studies, 'cross dressing, tattooing, women's fashions, dirty jokes and rock videos are routinely held up as examples of cultural resistance'. In the context of this essay, my use of the term is more literal. 'Resistance' to ritual violence consists of efforts to escape; scepticism and disavowal; discontinuance of custom; and remorse and shame. We shall find all represented in the literature, though less than might be expected, and less than we, while wearing our humanitarian hats, might wish. 


\section{The Clash of Values and the Origins of Resistance}

Standing against the opposition of men and women and the extremes of ritual violence are domestic relationships. In the case of the Ilahita Arapesh, domestic relationships are positive. Tuzin describes the 'extraordinary warmth and affection' between a man and his sister and between husband and wife. In marriage, there is a sense of spiritual harmony that begins with a new couple's 'pledge of eternal love and fidelity' (Tuzin 1982:329-30). The contradictions of domestic values and those of the men's cult are likely to be especially serious in this setting, and we shall see that it is just those values that seem to explain the scepticism and alienation that Ilahita men have from their own initiatory system.

Among the Sambia, however, marital relationships are strained to the point of disintegration. Women come from enemy villages; they may be 'stolen' or traded. 'Sex', Herdt writes, 'is fraught with anxiety. Physical fights are common... Sambia wife beating occurs and it is an ugly stain on the tenor of village life' (1981a:174).

But even among the Sambia, marriage confers a lifelong bond and has at least a measure of happiness. One of Herdt's informants notes: 'When a couple walk together from the forest, and everyone sees you returning from the gardens, your family and friends are happy for you' (Herdt 1981b:189). Following Herdt, 'joy is undeniably there for a moment' (1981b). At minimum, even in the most polarised of the Melanesian societies, men are bound to women for their own identity: 'only a wife and children bring full manhood' (Herdt 1981a:34).

Primary relationships stand in stark contrast with the ritual violence associated with the cults. The affection of husbands and wives and parents and children is incompatible with the extremes of initiation. Conflict within the family expresses the disjunction, in that the world of men is partly rejected by both boys and their mothers. Hence, among the Sambia, boys almost always side with their mothers in marital conflicts: 'Boys express anger and fear towards their fathers over this abuse of their mothers. I have seen boys try to hit their fathers in defense of their mothers' (Herdt 1981a:174).

The love of mothers for their sons spills over into the sacred territory of initiation rituals. Sometimes their resistance is symbolic in that they might put up a pretence of shielding their sons from masked initiators. But at other times it is a serious battle. Herdt describes an altercation of more than an hour as mothers 'attempt to extract their sons from the crowded dance ground...there are scuffles and arguments. Several times men angrily curse the women, who move back only to approach again...the atmosphere is tense enough for a brawl.' 
The men respond by attacking the women; 'more startling is the treatment of the mothers who are hit even harder by the men...some are hit hard enough so that they fall on the ground' (Herdt 1981a:137).

\section{Efforts to Escape}

The most unmistakable signs of resistance are the efforts of the initiates to flee. They scream, shout and cry and try to run away. The most dramatic examples I have found are Herdt's sensitive observations of the Sambia:
A boy refuses to be hoisted on his sponsor's back...it takes three men to do the job. His mother approaches...he grabs hold of her bamboo necklace...tears wash down his face as he repeatedly cries 'No, no,' and 'Mother, mother.' The poor woman...is nearly in tears herself...the men severely swat the boy with blow after blow. (Herdt 1981a:137)

One of the boys 'struggles fiercely, so four men lift him off the ground, he is forcibly nose-bled...the smell of blood and fear sours the air' (Herdt 1981a:143).

Herdt further documents that boys sometimes actually do escape, albeit briefly. When they do, search parties are sent out, and when the boys return they are beaten and treated more severely as a consequence. The central point that Herdt makes is ultimately obvious to the boys: there is no escape. All boys must be initiated. The fact that they resist at all, however, forms essential data. Despite the obvious rewards of maturity, they do not enter manhood gladly.

\section{Shame}

Men's cults - with their clash of domestic and cult values - are inherently unsteady edifices. One of the markers of instability is shame in perpetuating them. Among the Sambia, the men are deeply ashamed of their homosexual relations with one another and of forcing their sons to fellate the bachelors. The matter was a deep secret, revealed at pain of death.

Tuzin also describes the shame of the men in deceiving both the women and the initiates:

Aware that much of what passes for religious 'truth' is nothing but artifice, cult members are placed in the embarrassing position of having to confess to initiates that they - the initiates - have been systematically deceived... [They] openly admit that they feel deeply shamed at having their true role revealed to their sons. (Tuzin 1982:349) 
For fathers, the gulf between the cult and reality is so wide that they seek to put off the inevitable day when their sons learn that by their father's own standards, the voice of the Tambaran cult spirit is a fraud.

\section{Rationalisations}

A 'rationalisation' differs from 'an explanation' in that it is an intellectualised defence from guilt or remorse. The data are not always sufficiently fine-grained to make this claim. Thus, indigenous explanations of initiation emphasise the separation of boys from women and the magical techniques needed to make men of them. Following Herdt, '[m]en are doing boys a favor in initiating them'. The torments 'are directed at the boys' contaminated innards, which, alas, must be violently penetrated to cleanse them' (Herdt 1982:225-6). Is this a rationalisation or an explanation? I believe it is the former, in that the torments inflicted on the initiates are extreme, and the men's anger towards the boys is visceral. I have already described how the men tell the boys that they are being punished (which does not fit the prevailing ethos of making men out of boys), and they must at times be restrained from doing permanent physical harm. Tuzin captures the implicit sadism of the rituals when he notes that even if the torments are intended positively, they are also acts 'of raw aggression and dominance assertion' (1980:74). Moreover, 'the ordeal is carefully and successfully designed to inspire maximum horror on its victims' (Tuzin 1980). In the case of the Sambia, we learn that when 'the boys are carried through a gauntlet of men with whips...the men take delight in it. Most of the initiates cry' (Herdt 1981a:137).

Among the Avatip (a middle Sepik society), men scarify the boys to purge them of female blood. But they claim that the boys have been 'gored by spirits, whom they portray as anthropomorphic beings with tusks' (Harrison 1985:418). Harrison (1985) directly interprets this as a 'concession to the values prevailing outside the ritual sphere'. It is certainly that, but that such concessions are needed at all suggests the fragility of the enterprise and the real possibility of shame and guilt, which are but one step away from active resistance.

\section{Scepticism and Disbelief}

Donald Tuzin's work is unique in that he closely explored the scepticism and moral uncertainty that marked the Ilahita cult. The cult persisted in its island of secrecy but was everywhere else challenged by positive domestic relationships. These erode certainty about the contaminating nature of women and ultimately subvert masculine ideology. Tuzin writes that 
more than once it was intimated to me that just as the fiction of the physical [spirit] Nggwal enables men to dominate women, so the invisible Nggwal enables the senior initiates to dominate the junior colleagues. The lie is itself a life. Astonished upon hearing this I asked my informant, 'What, then, is the truth about the Nggwal?' to which he replied 'Nggwal is what men do'. (Tuzin 1982:348)

How did the cult persist in the face of such scepticism? Tuzin argues that the men's cult is 'a cultural addiction, in which the pain of continuing these ritual customs is exceeded only by the pain of relinquishing them' (1982:350).

Disbelief is surely an example of 'resistance'. Herdt, however, objects. He suggests that Tuzin's perspective is culture bound and not that of the Arapesh. He argues that the apparent guilt really reflects a post-colonial world, in which the heart of the cult has been eaten out by the pressures of evangelism and social change (Herdt 2003:205-7). The statement that the Tambaran is 'what men do' suggests that faith in Nggwal is at the end of a process of cultural change and 'the dissolution of collective ritual into alienation' (Herdt 2003:207). Had the Ilahita men's cult been in full flower, presumably Tuzin would not have observed this scepticism, which, like the underlying guilt, would seem to be a sentiment 'reminiscent of Western middle class emotional constraints' (Herdt 2003:195).

Tuzin might respond that primary relationships and men's cults are in chronic disequilibrium. The imbalance among the Ilahita Arapesh leads to a degree of reflection and eventually to disenchantment and alienation. It is inherent to the system; 'there is no reason to suppose that these reservations are not as ancient as the beliefs themselves' (Tuzin 1980:315).

Herdt's argument is more complex and sophisticated than we can do justice to here. But I would argue that scepticism is normal in human affairs, that doubters and local atheists are recurrent features of all social landscapes. Melanesian men's cults, however, would appear to be fertile ground for scepticism in that the values of the cult are in such radical conflict with primary relationships. Secrecy, as Herdt (2003) convincingly documents, makes it possible to sustain both in their separate compartments, but it surely saps faith and credibility. To an extent, even the Sambia recognise this. Hence, by the logic of equating semen with breast milk, fathers should inseminate sons to make men of them, just as mothers nursed boys. But of course this does not occur, despite its theoretical plausibility. And in no case of which I am aware do fathers inflict the most painful initiatory torments on their sons. There is, therefore, a separation between domestic life and the cult, and from this space might grow resistance to the formal system. 
Scepticism and ambivalence might therefore be more than the bitter fruits of culture contact, force-fed by judgmental officials, police patrols and missionaries. Societies are not homogeneous and individuals are reflective even if their voices are drowned out or actively suppressed by the chorus of believers and enforcers. There are simply too many losers in the Ilahita, Sambia and other initiatory systems for them to go without dissent. Surely, throughout initiatory societies, there are mothers and fathers who would prefer that their sons opt out, and I am quite sure the same thought has regularly occurred to the initiates themselves. Senior men might be beneficiaries, but not women, not children, not initiates manqué, not 'rubbish men' and not others who were marginalised by the system.

Finally, we note the rapid collapse of such systems, as occurred among the Sambia with the suppression of war. Herdt (Email, 14 December 2010) informs me that not only has initiation ceased, but also the entire men's cult is a thing of the past. Tuzin's (1997) own account of the spontaneous self-destruction of the Ilahita men's cult makes the same point just as dramatically. Men's cults are fragile, if dark, institutions, narrowly adapted to overwhelming need for masculine solidarity. But they are fraught with contradiction, which we can observe even while the system is in place.

\section{Conclusions}

Why does the suffering of the initiates disturb us, and why are we motivated to seek resistance to it? I began this chapter by suggesting that we have no true analogue to ritual violence. The closest approximation we have is that of torture - a deeply evaluative word that anthropologists avoid in describing the ordeals. We can, however, find many superficial resemblances between torture and the ordeals in their exquisiteness, their technology and their intuitive understanding of how to violate the human self. As Tuzin says of Ilahita, the cult 'engenders acts that are physically, emotionally, or, indeed, fantastically terrorist' (1982:347). But if we grant some resemblance, it shifts the direction of the question: why is torture repugnant? The answer would seem to lie in the intentionality of the act, the physical closeness of the torturer and the victim and the relationship of the two. What torture violates is the fundamental human capacity for empathy, upon which all morality is ultimately based. Ariel Dorfman, a Chilean essayist, wrote: 'Torture...requires, it craves the abrogation of our capacity to imagine others' suffering, dehumanizing them so much that their pain is not our pain.' In other words: 'Torture obliges us to be deaf and blind and mute' (Dorfman 2007). 
The fact of resistance shows that initiators are hardly indifferent. But at times the raw sadism of many of the acts, in which the higher purposes of the ordeals might not even be explained to the victims, point in another direction. What overwhelming rage can nourish such an institution so that it was not only invented and enacted, but also perpetuated by those who suffered at its hands? This question takes us in a different direction. We might invoke the reasons offered by Whitehouse and Morinis in their discussion of pain, and the need to create a firmly bonded group of men. The psychological mechanisms that facilitate this process such as identification with the aggressor and its association with traumatic stress disorder might also be part of it. But does this suggest that the pattern is pathological, and that the society itself, is, by extension, emotionally disturbed? Many anthropologists are uncomfortable with such judgments because we lack a clear standard for diagnosing a society's mental status as opposed to that of an individual. In the present instance, the sum total of behaviour associated with men's cults has the look of pathology but does it have its substance? Freud, who did not hesitate to read culture and behaviour as if they constituted a single personality, was himself aware of the danger of conflating the two. Hence, he noted that the striking resemblance of taboos and the obsessive-compulsive neurosis 'may be no more than a matter of externals, just as the branching structure of trees and crystals are essentially unrelated' (Freud 2004:31).

Are men's cults therefore simply unusual cultural scripts, or, in Tuzin's terms, 'cultural addictions', but not reflective of individual personality? I am inclined to believe otherwise. The ego-dystonic nature of the cults, with their concomitant rationalisations and sense of shame, is all too suggestive. The fact that the cults might collapse from the internal weight of moral ambivalence (as in the case of the Ilahita), or with a relatively gentle external nudge (as in the instance of the Sambia), is further evidence. Finally, the inventive nature of the sadism, and the extraordinary brutality towards initiates, is surely deeply rooted in primary process thought.

For the moment, however, it is enough to say that the participants in the cults are not themselves of one mind. Ideology and conduct are sufficiently disjoined so that some do object. They distance themselves from the initiations, they disbelieve, they resist. This does occur-less frequently than we might wish, but often enough to at least partly dispel Freud's bleak view of the human condition with which I began this chapter. 


\section{References}

Bateson, Gregory 1958. Naven. Stanford, Calif.: Stanford University Press.

Bettelheim, Bruno 1954. Symbolic Wounds. Glencoe, Ill.: The Free Press.

Brown, Michael F. 1996. On Resisting 'Resistance'. American Anthropologist98:729-35.

Campbell, Joseph 1983. Historical Atlas of World Mythology. San Francisco: Harper \& Row.

Dorfman, Ariel 2007. Are There Times When We Have to Accept Torture? Are We Really So Fearful? South Central Review 24:95-100.

Freud, Sigmund 2004. Taboo and Emotional Ambivalence. In Totem and Taboo. London: Routledge.

Gregor, Thomas 1985. Anxious Pleasures: The Sexual Lives of an Amazonian People. Chicago: University of Chicago Press.

Gregor, Thomas A. and Donald F. Tuzin 2001. The Anguish of Gender: Myths of Matriarchy and Men's Cults in Amazonia and Melanesia. In Thomas A. Gregor and Donald F. Tuzin (eds) Gender in Amazonia and Melanesia: An Exploration of the Comparative Method, pp. 309-36. Berkeley: University of California Press.

Harrison, Simon J. 1985. Ritual Hierarchy and Secular Equality in a Sepik River Village. American Ethnologist 12:413-26.

Hays, Terrence 1988. 'Myths of Matriarchy' and the Sacred Flute Complex of the Papua New Guinea Highlands. In Deborah Gwertz (ed.) Myths of Matriarchy Reconsidered, pp. 98-120. Oceania Monograph 33. Sydney: University of Sydney Press.

Herdt, Gilbert 1981a. The Sambia: Ritual and Gender in New Guinea. New York: Holt, Rinehart \& Winston.

Herdt, Gilbert 1981b. Guardians of the Flutes: Idioms of Masculinity. New York: McGraw-Hill.

Herdt, Gilbert 1982. Sambia Nosebleeding Rites and Male Proximity to Women. Ethos 10:189-231.

Herdt, Gilbert 2003. Secrecy and Cultural Reality: Utopian Ideologies of the New Guinea Men's House. Ann Arbor, Mich.: University of Michigan Press. 
Hiatt, L. R. 1971. Secret Pseudo-Procreation Rites Among the Arunta Aborigines. In L. Hiatt and C. Jayawardena (eds) Anthropology in Oceania: Essays Presented to Ian Hogbin, pp. 77-88. Sydney: Angus \& Robertson.

Keesing, Roger M. 1982. Introduction. In Gilbert H. Herdt (ed.) Rituals of Manhood: Male Initiation in Papua New Guinea, pp. 1-43. Berkeley: University of California Press.

Knauft, Bruce M. 1993. South Coast New Guinea Cultures: History, Comparison, Dialectic. Cambridge: Cambridge University Press.

Lindenbaum, Shirley 1987. The Mystification of Female Labors. In J. Collier and S. J. Yanagisako (eds) Gender and Kinship: Essays Towards a Unified Analysis, pp. 221-43. Stanford, Calif.: Stanford University Press.

Morinis, Alan 1985. The Ritual Experience: Pain and the Transformation of Consciousness in Ordeals of Initiation. Ethos 13:150-74.

Newman, Philip L. and David J. Boyd 1982. The Making of Men: Ritual and Meaning in Awa Male Initiation. In Gilbert H. Herdt (ed.) Rituals of Manhood: Male Initiation in Papua New Guinea, pp. 239-85. Berkeley: University of California Press.

Read, Kenneth E. 1954. Cultures of the Central Highlands. Southwestern Journal of Anthropology 10:1-43.Read, Kenneth E.

Read, Kenneth E 1965. The High Valley. New York: Charles Scribners and Sons.

Tuzin, Donald F. 1980. The Voice of the Tambaran: Truth and Illusion in Ilahita Arapesh Religion. Berkeley: University of California Press.

Tuzin, Donald F. 1982. Ritual Violence Among the Arapesh: The Dynamics of Moral and Religious Uncertainty. In Gilbert H. Herdt (ed.) Rituals of Manhood: Male Initiation in Papua New Guinea, pp. 321-55. Berkeley: University of California Press.

Tuzin, Donald F. 1997. The Cassowary's Revenge: The Life and Death of Masculinity in a New Guinea Society. Chicago: University of Chicago Press.

Whitehouse, Harvey 1996. Rites of Terror: Emotion, Metaphor and Memory in Melanesian Initiation. The Journal of the Royal Anthropological Institute 2:703-15. 